\title{
DESCRIÇÃO DE DUAS ESPÉCIES NOVAS DE OPOPAEA DO SUL DO BRASIL (OONOPIDAE, ARANEAE)
}

\section{Ricardo Ott ${ }^{1}$}

\begin{abstract}
DESCRIPTION OF TWO NEW SPECIES OF OPOPAEA FROM SOUTH OF BRAZIL (OONOPIDAE, ARANEAE). Two new species, Opopaea viamao and $O$. ita, are described from the states of Rio Grande do Sul and Santa Catarina, Brazil, respectively. Both species present reduction or loss of posterior median eyes, a possible synapomorphic caracter.
\end{abstract}

KEYWORDS. Gamasomorphinae, Brazil, Neotropical, taxonomy.

\section{INTRODUÇÃO}

A família Oonopidae inclui aranhas haplóginas com 1 a $3 \mathrm{~mm}$ de comprimento corporal. São aranhas errantes, habitantes de regiões de clima tropical e subtropical, encontradas preferencialmente na serapilheira, sob casca de troncos de árvores e algumas em vegetação arbustiva.

A base da taxonomia da família foi proposta por Simon (1893), com duas subfamílias: Gamasomorphinae, caracterizada pela presença de escudos abdominais e Oonopinae, na qual estas estruturas estão ausentes. Segundo BRIGNOLI (1978), o sistema proposto por Simon é insatisfatório para delimitação dos gêneros, uma vez que se baseia exclusivamente em características somáticas como, presença ou ausência de escudos no abdômen, presença ou ausência de espinulação nas pernas anteriores e posição dos olhos, com pouca ênfase na morfologia da genitália.

A subfamília Gamasomorphinae conta atualmente com 31 gêneros, dos quais 11 contêm espécies descritas para a América do Sul (Platnick, 2002): Decuana Dumitrescu \& Georgescu, 1987; Dysderina Simon, 1891; Eusimonia Dumitrescu \& Georgescu, 1987, Gamasomorpha Karsch, 1881; Hytanis Simon, 1892; Marsupopaea Cooke, 1972; Myrmecoscaphiella Mello-Leitão, 1926; Neoxyphinus Birabén, 1953; Opopaea Simon, 1891; Prodysderina Dumitrescu \& Georgescu, 1987; Scaphiella Simon, 1891. BIRABÉN (1954) e Dumitrescu \& Georgescu (1987) trataram dos gêneros sul-americanos de Gamasomorphinae. A maioria destes inclui apenas uma ou duas espécies. Gamasomorpha tem o maior elenco, com 11 espécies descritas.

1. Museu de Ciências Naturais, Fundação Zoobotânica do Rio Grande do Sul, Rua Dr. Salvador França, 1427, 90690-000, Porto Alegre, RS, Brasil. (aracno@fzb.org.br) 
O gênero Opopaea conta, atualmente, com cinco espécies neotropicais e apenas duas ocorrentes na América do Sul: O. cupida (Keyserling, 1882), da Colômbia e $O$. guaraniana Birabén, 1954, da Argentina. A espécie-tipo do gênero é $O$. deserticola Simon, 1891, descrita para a Ilha de São Vicente, nas Antilhas. Características genéricas incluem: ausência de espinhos nas pernas anteriores; espessamento, em maior ou menor grau, da patela, no palpo dos machos; bulbo copulatório parcial ou totalmente fusionado ao címbio; êmbolo distal; condutor ausente; sulcos radiais no esterno; abertura copulatória feminina estreita; escudo abdominal ventral com uma estrutura em forma de " $\mathrm{H}$ ", visível por transparência, constituída pelos apódemas internos e uma esclerotinização transversal que se estende entre os espiráculos traqueais posteriores (BIRABÉN, 1954; BRIGNOLI, 1974, 1975, 1978, 1980; Burger et al., 2002; Dumitrescu \& GEORGESCu, 1983).

Ambas as espécies, descritas a seguir, apresentam redução ou ausência dos olhos médios posteriores, possivelmente um caráter sinapomórfico para as mesmas. A inclusão de espécies com diferente número de olhos, em um mesmo gênero, é registro conhecido para a família Oonopidae (HöFER \& BRESCOVIT, 1996). A presença de escudos abdominais fusionados e pouco esclerotinizados, presente em uma das espécies descritas, constitui caráter desconhecido para o gênero até o momento.

O material estudado está depositado nas coleções aracnológicas do MCTP, Museu de Ciências e Tecnologia da Pontifícia Universidade Católica do Rio Grande do Sul, Porto Alegre (Arno A. Lise) e do MCN, Museu de Ciências Naturais, Fundação Zoobotânica do Rio Grande do Sul, Porto Alegre (Erica H. Buckup). As medidas estão em milímetros.

\section{Opopaea viamao sp. nov.}

(Figs.1-4)

Tipos. Holótipo đ (MCTP 8821), Viamão, Rio Grande do Sul, Brasil, 07.XI.1995, R. Ott. Parátipo ơ (MCTP 8822), mesma localidade do holótipo, 10.V.1996, R. Ott.

Etimologia. O substantivo em aposição refere-se à localidade-tipo.

Diagnose. O macho de Opopaea viamao é reconhecido por apresentar apenas quatro olhos, olhos médios posteriores ausentes (fig. 3); patela do palpo pouco espessada; bulbo totalmente fusionado ao címbio; êmbolo recurvado, com ápice rombo e larga lamela basal que se estreita distalmente (fig. 4).

Macho (holótipo): coloração geral castanho-clara. Comprimento total 1,25. Cefalotórax castanho-claro, comprimento 0,52, largura 0,38, altura 0,16. Clípeo 0,02. Olhos de igual tamanho, diâmetro 0,03; sem tapetum. Comprimento da área ocular 0,08, largura anterior 0,08, largura posterior 0,10. Esterno com estrias radiais (figs. 1, 2), levemente granuloso, comprimento 0,38, largura 0,30. Abdômen castanho-claro, comprimento 0,62, largura 0,36, altura 0,27. Escudo dorsal recobrindo quase todo o abdômen, escudo ventral não alcançando as fiandeiras, estas cercadas por um anel pouco esclerotinizado. Pernas amareladas, comprimento relativo: 4123; I - fêmur 0,32 / patela 0,18 / tíbia 0,24 / metatarso 0,18 / tarso 0,12; II - 0,30 / 0,18 / 0,20 / 0,16/ 0,14; III - 0,24 / 0,14 / 0,16/ 0,14 / 0,12; IV - 0,34 / 0,18 / 0,28 / 0,22 / 0,16. Fêmea, desconhecida.

Variação (parátipo). Comprimento total 1,10; abdômen 0,62. 

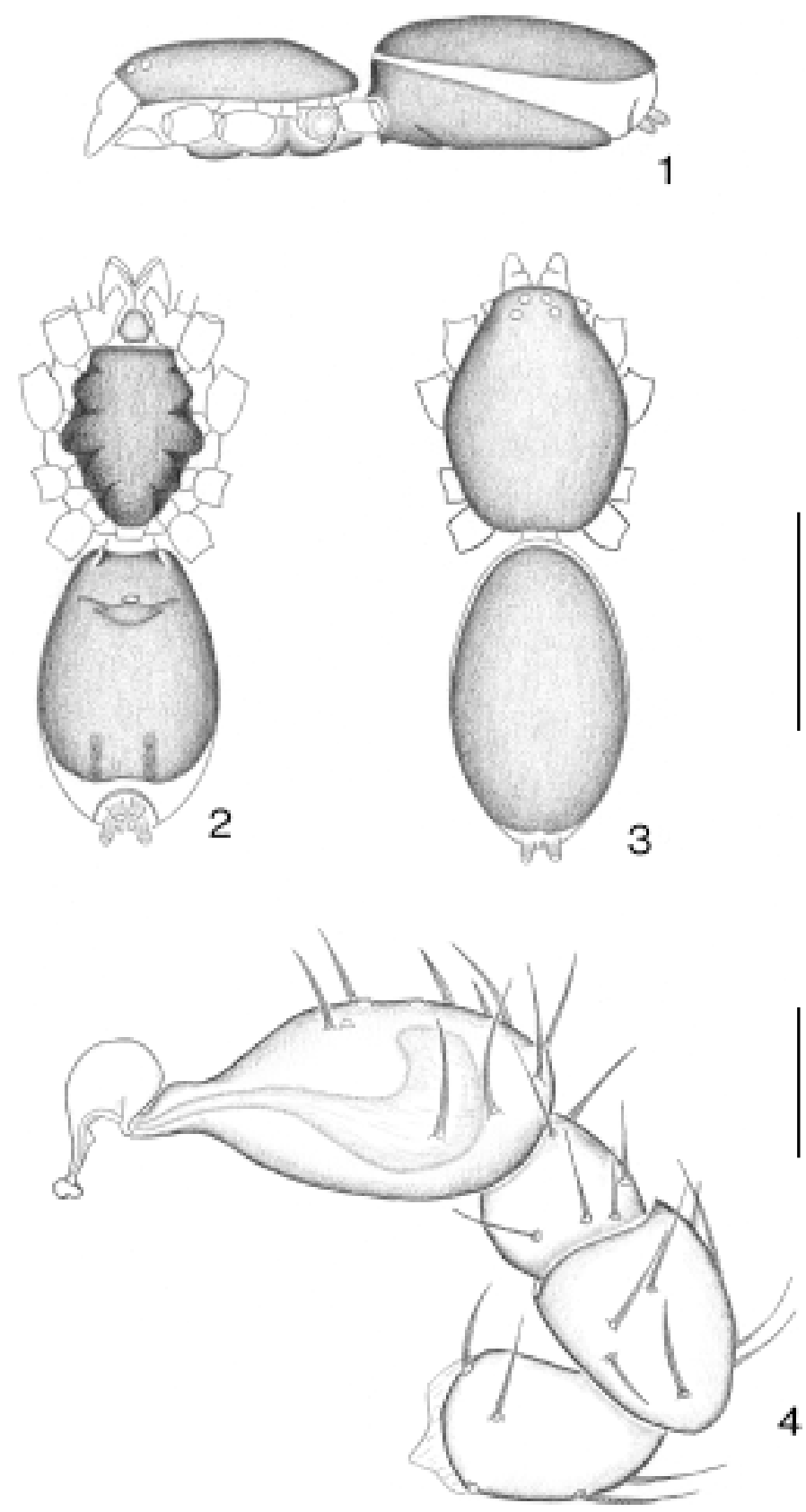

Figs. 1-4. Opopaea viamao sp. nov.: 1, cefalotórax e abdômen lateral; 2, ventral; 3, dorsal; 4, palpo retrolateral. Figs. $1-3$, barra $0,5 \mathrm{~mm}$; fig. 4 , barra $0,05 \mathrm{~mm}$. 

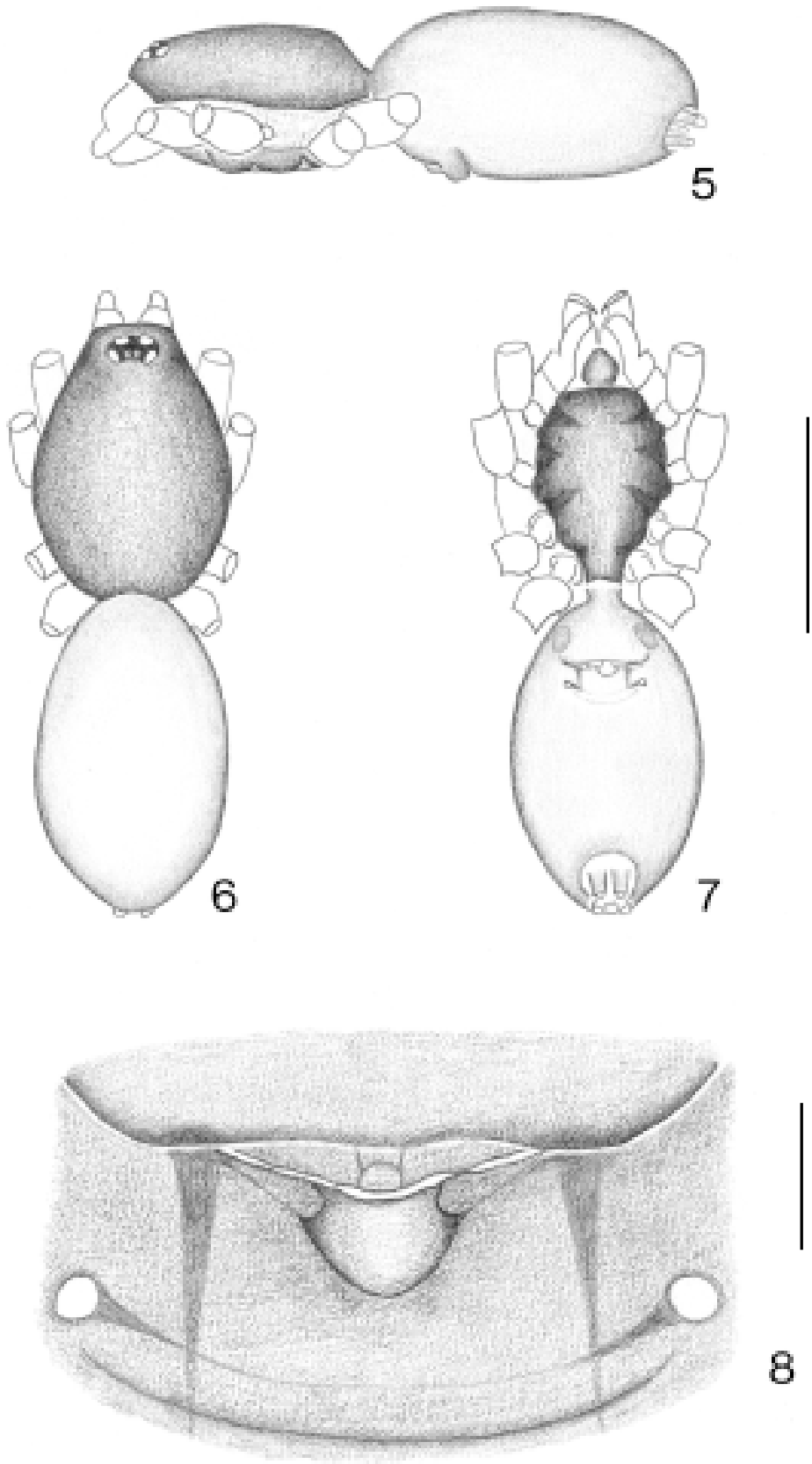

Figs. 5-8. Opopaea ita sp. nov.: 5, cefalotórax e abdômen lateral; 6, dorsal; 7, ventral; 8, placa genital ventral. Figs. $5-7$, barra $0,5 \mathrm{~mm}$; fig. 8 , barra $0,05 \mathrm{~mm}$. 
História natural. A espécie foi encontrada apenas em serapilheira, podendo ser considerada rara, com apenas dois exemplares em um total de 2690 aranhas coletadas ao longo de um ano de amostragem.

\section{Opopaea ita sp. nov.}

(Figs. 5-8)

Tipo. Holótipo $\subsetneq$ (MCN 27141), Rodovia Nova Teotônia-Itá (2711'00"S - 52 29’01"W), Santa Catarina, Brasil, 01.IV.1996, A. B. Bonaldo, A. Kury \& R. P. Rocha.

Etimologia. O substantivo em aposição refere-se à localidade próxima ao local de coleta.

Diagnose. A fêmea de Opopaea ita distingue-se das outras espécies do gênero pelos olhos médios posteriores de tamanho reduzido (fig. 6); epígino com nódulo mediano semi-circular e espiráculos traqueais posteriores circulares, ligados por uma linha levemente esclerotinizada (fig. 8).

Fêmea (holótipo). Comprimento total 1,37. Cefalotórax castanho, muito esclerotinizado, textura granulosa, comprimento 0,65 , largura 0,49 , altura 0,21. Clípeo 0,04 . Seis olhos, anteriores e laterais posteriores ovalados em vista dorsal, de igual tamanho; médios posteriores com cerca da metade do diâmetro dos demais. Comprimento da área ocular 0,08 , largura anterior 0,10 , largura posterior 0,14 . Esterno com estrias radiais (fig. 5,7), granuloso, comprimento 0,47 , largura 0,30 . Abdômen mais claro que o cefalotórax, pouco esclerotinizado, escudos abdominais não delimitados, formando único invólucro; comprimento 0,75 , largura 0,46 , altura 0,39 . Pernas castanhas, comprimento relativo: 4123; I - fêmur 0,44 / patela 0,22 / tíbia 0,32 / metatarso 0,25 / tarso 0,$14 ;$ II - 0,35 /0,19/0,27/0,24/0,12; III - 0,31/0,14/0,16/0,22 / 0,15; IV - 0,44/0,20/0,32/0,30/0,16. Região genital elevada (fig. 5). Macho, desconhecido.

Agradecimentos. Aos curadores das respectivas coleções pelo empréstimo de material e sugestões ao manuscrito. Aos revisores anônimos pelas sugestões.

\section{REFERÊNCIAS BIBLIOGRÁFICAS}

BirAbÉn, M. 1954. Nuevas Gamasomorphinae de la Argentina (Araneae, Oonopidae). Notas Mus. La Plata, La Plata, 17(152):181-212.

Brignoli, P. M. 1974. On some Oonopidae from Japan and Formosa (Araneae). Acta Arachnol., Osaka, 25(2):73-85.

1975. Ragni del Libano. I. Nota su Opopaea punctata (O. Pickard-Cambridge, 1872) ed altre specei dello stesso genere (Araneae, Oonopidae). Fragm. ent., Roma, 11(3):223-233.

1978. Araneae: Fam. Oonopidae, Agelenidae, Hahniidae und Mimetidae. Ent. Basil., Basel, 3:31-56. (Ergebnisse der Bhutan-Expedition 1972 des Naturhistorischen Museums in Basel).

1980. Two new haplogynae from Thailand (Araneae). Steenstrupia, Copenhagen, 6(2):5-8.

Burger, M; Nentwig, W. \& Kropf, C. 2002. Opopaea fosuma, n. sp. from Sumatra, Indonesia (Araneae, Oonopidae). Bull. Br. Arachnol. Soc., London, 12(5):244-248.

Dumitrescu, M. \& Georgescu, M. 1983. Sur les Oonopidae (Araneae) de Cuba. In: Résultats des expéditions biospéologiques cubano-roumaines à Cuba, Bucaresti, Academici Republicii Socialiste Romania. Part 4, p. 65-114.

_. 1987. Quelques représentants de la famille Oonopidae (Araneae) du Venezuela. In: Fauna 
hipogea y hemiedáfica de Venezuela y de otros paises de América del Sur. Bucaresti. v. 1, part 9, p. 89-105.

Höfer, H. \& Brescovit, A. D. 1996. On the genus Xyccarph in central Amazonia (Araneae: Oonopidae). Bull. Br. arachnol. Soc., London, 10(4):149-155.

Platnick, N. I. 2002. The World spider catalog, version 3.0. American Museum of Natural History, online at http://research.amnh.org/entomology/spiders/catalog81-87/index.html. 23 de julho de 2002.

Simon, E. 1893. Histoire naturelle des Araignées. Paris, Librarie Encyclopedique de Roret. v. 1 , fasc. 2, p.257-487. 